\title{
Carbon Quantum Dots: Synthesis, Characterization and Biomedical Applications
}

\section{Karbon Kuantum Noktaları: Sentez, Karakterizasyon ve Biyomedikal Uygulamalar}

\author{
(D) Inderbir SINGH ${ }^{1 *}$, (D) Riya ARORA 1 , (D) Hardik DHIMAN', (D) Rakesh PAHWA² \\ ${ }^{1}$ Chitkara University, Chitkara College of Pharmacy, Department of Pharmaceutics, Punjab, India \\ ${ }^{2}$ Kurukshetra University, Institute of Pharmaceutical Sciences, Haryana, India
}

\begin{abstract}
CQD are small carbon nanoparticles smallerl than $10 \mathrm{~nm}$ comprising distinctive properties, which have become an obligatory tool for traceable targeted delivery, biomedical research, and different therapy applications. The objective of the present work was to consolidate the current literature on the synthesis, characterization techniques, and biomedical applications of CQD. Two types of synthetic methods viz. top-down approach and bottom-up approach were used for the synthesis of CQD. The top-down approach includes the arc-discharge method, laser ablation method, and electrochemical method. The bottom-up approach includes the thermal method, microwave-assisted method, hydrothermal and aqueous method, and the template method. In this review, we explain the recent progress of CQD in the biomedical field, focusing on their synthetic methods and characterization, followed by different applications. Carbon dots have extensive adequacy for in vivo and in vitro bioimaging and drug delivery studies. Although more cytotoxicity studies of carbon dots are needed, the data above suggest a bright future for carbon dots in drug delivery and bioimaging studies.
\end{abstract}

Key words: Carbon quantum dots, nanoparticles, quantum yield, carbon dots, photoluminescence, nanocomposites

öz

KKN, ayırt edici özellik olarak, 10 nm'den daha küçük boyutu olan, küçük karbon nanopartiküllerdir ve izlenebilir hedeflenmiş salım, biyomedikal araştırma ve farklı terapi uygulamaları için zorunlu bir araç haline gelmiştir. Bu çalışmanın amacı, KKN'nın sentezi, karakterizasyon teknikleri ve biyomedikal uygulamaları ile ilgili güncel literatürü bir araya getirmekti. KKN sentezi için iki tip yapay yöntem yani yukarıdan aşağıya yaklaşım ve aşağıdan yukarıya yaklaşım kullanıldı. Yukarıdan aşağıya doğru yaklaşım, ark boşaltma yöntemini, lazer ablasyon yöntemini ve elektrokimyasal yöntemi içermektedir. Öte yandan aşağıdan yukarı yaklaşım, termal yöntem, mikrodalga destekli yöntem, hidrotermal ve sulu yöntem ve kalıp yöntemini içerir. Bu derlemede, CQD'nin biyomedikal alanda son dönemdeki ilerlemesini, sentetik yöntemlerine, karakterizasyonuna ve farklı uygulamalara odaklanarak açıkladık. Karbon noktaları, in vivo ve in vitro biyolojik görüntüleme ve etken madde salım çalışmaları için kapsamlı yeterliliğe sahiptir. Karbon noktaları için daha fazla sitotoksisite araştırması yapılmasına ihtiyaç duyulmasına rağmen, önceki veriler etken madde salımı ve biyolojik görüntüleme çalışmalarında karbon noktalarının parlak geleceğini göstermektedir.

Anahtar kelimeler: Karbon kuantum noktalar, nanopartiküller, kuantum verimi, karbon nokta, fotolüminesans, nanokompozitler

\section{INTRODUCTION}

Luminescent semiconductor nano crystals of size 1-10 nanometers with rich surface chemistry and unique optical properties are called quantum dots (QDs). Different compounds belonging to group 2 to 4 and 3 to 5, e.g., $\mathrm{Ag}, \mathrm{Cd}, \mathrm{Zn}, \mathrm{Hg}$, Se, $\mathrm{Ln}, \mathrm{Pb}, \mathrm{P}$, and $\mathrm{Te}$ lead to the formation of QDs. These have become an obligatory tool for traceable targeted delivery, biomedical research, and different therapy applications. Longterm fluorescence imaging and the detection of the properties of these nanoparticles (NPs) have made them imperative in biomedical research. Different properties of QDs such as resistance to photobleaching, superior signal brightness, larger absorption coefficients, light emission, and contemporaneous excitation of different fluorescence colors make them unique, as well as indispensable. Advances in quantum surface chemistry studies have led to the development of polymer-encapsulated probes with high fluorescence properties that are stable under complex biologic conditions. To use QDs in biologic studies, it is extremely important to cap or passivate the $\mathrm{ZnS}$ or CdS layer around the QD (CdSe). This layering of $\mathrm{ZnS}$ or CdS leads to the improvement of the fluorescence quantum yield (QY) of QDs and provides protection against photo-oxidation. QDs have had a major impact in molecular diagnostics and in tissue molecular 
biology. The basic purpose in opting for QDs emerged from their incomparable and engrossing optical properties, which are not generally feasible for an individual molecule or bulk semiconductor, in addition to resistance against photobleaching. They have the ability to elucidate the pharmacokinetics and pharmacodynamics of drug applicant and serve as a "traceable" drug delivery system. ${ }^{1-5}$ In 1984, the Russian physicist Ekimov first discovered QDs in glass crystals. After 1984, a systemic advancement in pharmaceutical sciences was driven, and a relationship was established between the size and band gap for semiconductor nano particles (by applying a particle in a sphere model) approximation to the wave function for bulk semiconductors. In the beginning, the studies were limited to $\mathrm{CdSe} / \mathrm{CdS}$ and CdSe/ZnS QD, but later on, other "core-shell" QDs were developed and studied, e.g., ZnSe/CdSe.

Cadmium was the chief component in the composition of traditional QDs, but the use of cadmium was limited because leakage of cadmium ions leads to cytotoxicity. ${ }^{5}$ The cytotoxicity caused by leaked cadmium ions led to the discovery of more biocompatible QDs. With the increasing demand for more biocompatible QDs, the emphasis shifted toward the development of cadmium-free QDs with high chemical stability, low toxicity, and different pharmaceutic applications. This led to the formation of different QDs such as carbon QD (CQDs), graphene QDs, and silicon QDs.5,6 CQDs were first obtained through the purification process of single-walled carbon nanotubes through preparative electrophoresis in 2004. They were first indicated as 'carbon NPs (CNP)' but later adopted the name 'carbon dots (C-dots)', eliciting similar properties to inorganic QDs. C-dots have gathered wide attention and considerable potential in biologic applications. Also, biocompatibility has been touted as the main lead of $\mathrm{C}$-dots in the branch of NPs applications. C-dots mainly consist of carbon, which is an abundant and nontoxic element, and they endow distinguished structural and electronic properties that are different from other NPs families. ${ }^{5}$ Advanced device applications were achieved for QDs when their intrinsic properties were successfully tuned by doping with heteroatoms. Because of their biocompatibility, low toxicity, strong photoluminescence $(P L)$, synthetic and photograph steadiness, C-dots have become a fascinating material for bioimaging and the detection of different analytes. C-dots ordinarily contain discrete, quasispherical NPs with sizes less than $10 \mathrm{~nm}$. Sp $\mathrm{P}_{2}$ - characterized CQDs consist of different functional groups such as carbonyl, ether, epoxy, amino, carboxylic acid, and a hydroxyl group on their surface. The presence of such groups on C-dots leads to their high hydrophilicity. The captivating PL properties of C-dots are subject to their edge shape, size, deformities, and surface passivation. ${ }^{7}$ Highly bright CQDs, which are soluble in oil, can also be fabricated by hot injection with B and $\mathrm{N}$ codoping by taking 1,2-hexadecanediol as a carbon precursor and surface passivation material. $^{8}$

\section{Advantages of carbon quantum dots}

- Inexpensive-CQDs are inexpensive and abundant thus making them a rising star as a nanocarbon member.
- Photostability: stability and composition of CQDs lead to their greater photostability when compared with organic dyes and traditional QDs.

- Broader excitation and narrow emission: CQDs have a more sharply defined emission peak and broader excitation spectra than organic dyes and other cadmium-based QDs.

- Biologic properties: the superior biologic properties of C-dots, such as hydrophilicity, low toxicity, chemical stability, and good biocompatibility ensure their promised applications in biosensors, drug delivery, and bioimaging.

- Luminescence: greater luminescence as compared with other QD.

- Aqueous stability: CQDs have high aqueous stability as compared with other cadmium-based QDs and organic dyes.

- Electronic properties: outstanding electronic properties of carbon-based QDs as electron donors and acceptors cause the electrochemical luminescence and chemiluminescence, empowers them with broad potential in optronics, catalysis, and sensors.

- Chemical inertness: the chemical stability of C-dots is very high as compared with other QDs (traditional or metallic). ${ }^{9}$

\section{Synthesis}

Synthetic techniques for CQDs are categorized into two classes, 'bottom-up' and 'top-down' courses. These can be accomplished by means of chemical, electrochemical or physical systems. ${ }^{10}$ Top-down strategies involve the fragmentation of carbon matter into CNPs, and strategies comprising arc discharge, laser ablation, and electrochemical approaches. Bottom-up strategies incorporate template strategy, thermal routes, pyrolytic process, hydrothermal and aqueous methods, supported synthetic technique, reverse micelle technique, microwave-assisted strategy, and substance oxidation." The yield of CQDs could be enhanced during arrangement or posttreatment. Alteration of CQDs is additionally vital to obtain favorable surface properties, which are key for solvency and applications. ${ }^{12}$

- Moreover, carbon precursors, for example ground coffee, used tea leaves, grass, and light sediment are also used to develop C-dots. The development of $\mathrm{C}$-dots by these precursors is plentiful and economical..$^{10}$ In addition, a green approach for easy and one-step synthesis of fluorescent C-dots can be achieved from wool (natural and nontoxic substance) for sensing the glycophosate detection. ${ }^{13}$ Different synthetic approaches are mentioned in Figure 1.

\section{Top-down approaches}

\section{Arc-discharge}

This strategy can be employed to develop C-dots from crude carbon nanotube soot (sediment). The crude material (sediment) was oxidized with $3.3 \mathrm{M} \mathrm{HNO}_{3}$ to introduce carboxyl groups, the resulted matter was then extracted with $\mathrm{NaOH} /$ basic solution of $\mathrm{pH} 8.4$, a stable dark colored suspension was obtained. Gel electrophoresis was conducted to purify the extracted matter. ${ }^{10}$ Separation of a quick-moving band of highly 


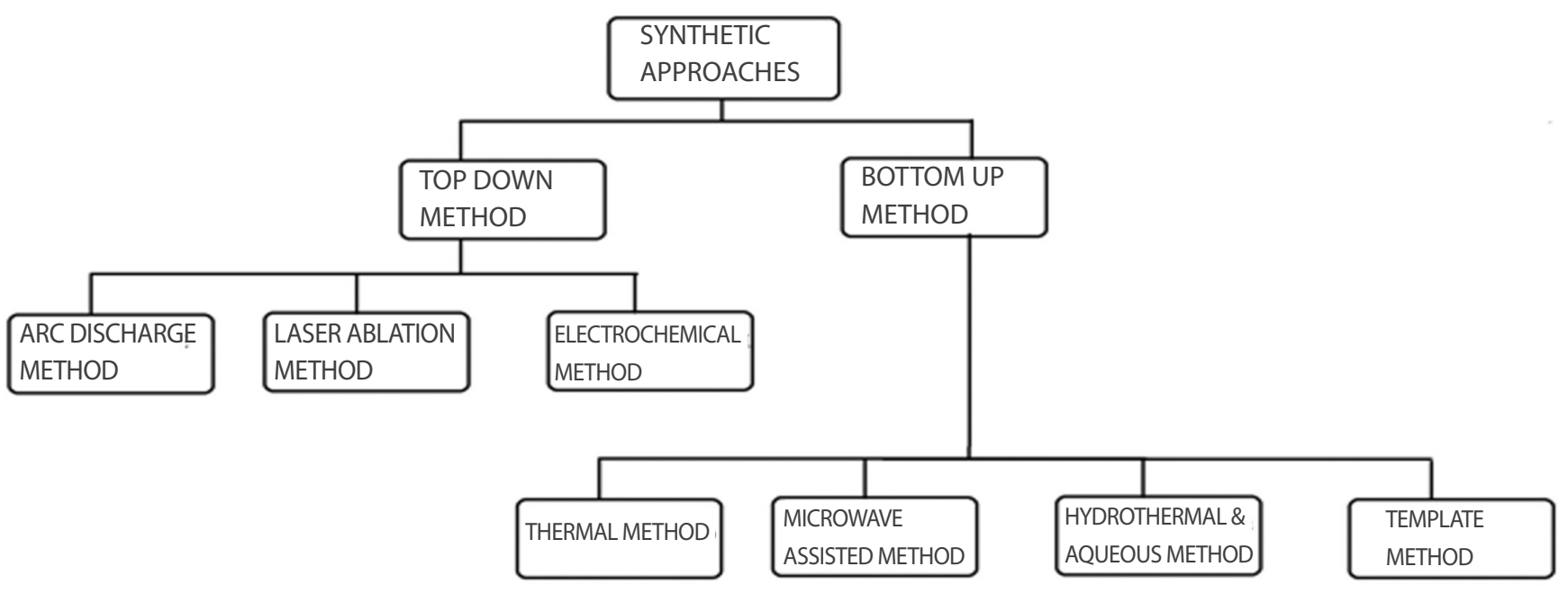

Figure 1. Different methods for the synthesis of carbon quantum dots

fluorescent carbon-dot was found to be $18 \mathrm{~nm}$. Pristine and nitric acid oxidized carbon nanotubes were employed to outline the photoluminescent NPs; the latter being developed using the electric arc technique. Fluorescent NPs derived by the pristine carbon nanotube were hydrophobic and possessed limited distribution. On the other hand, the fluorescent NPs derived by the oxidized carbon nanotube had the capacity to accumulate when scattered in water because they were externally combined with oxygen and covered by a thin layer of carbon and demonstrated a more extensive division. CNPs obtained by the arc discharge method have low yield, in addition, the arc discharge soot method comprises a number of composite segments. However, the purification of these segments was hard.11

\section{Laser ablation}

In this method, synthesis of fluorescent $\mathrm{C}$-dots is accomplished by laser irradiation of C-target (carbon target). Sun et al. ${ }^{14}$ initially heated a blend of cement and graphite powder in order to prepare a carbon target, then fabricated CNPs by means of laser ablation/removal of the carbon target in a stream of argon gas conveying water vapor at $900{ }^{\circ} \mathrm{C}$ and $75 \mathrm{kPa}$. The nanoscale carbon particles were obtained in aggregated form possessing different sizes with no distinguishable PL. An aqueous solution of $\mathrm{HNO}_{3}$ (nitric acid) was treated with the sample followed by refluxing for $12 \mathrm{~h}$, later polyethylene glycol (PEG1500N) or poly propionyl ethyleneimine-co ethyleneimine was reacted with the sample, and the passivated C-dots were highly photoluminescent, having size of about $5 \mathrm{~nm}$. With activation of these C-dots at $400 \mathrm{~nm}$, the fluorescence QY was around 4\% to more than $10 \% .^{11}$ In addition, doping of $\mathrm{C}$-dots with inorganic salts such as zinc acetate and $\mathrm{Na}_{2} \mathrm{~S}$ or $\mathrm{NaOH}$ further resulted in an enhanced QY, in which the dopants (e.g. ZnO and $\mathrm{ZnS}$ ) possibly served as a helper passivating mediator for the $\mathrm{C}$-dots. When activated at $450 \mathrm{~nm}$, doped C-dots showed strong PL (QY 45\%). PL C-dots of different colors were prepared in different solvents and aqueous medium, provided that the organic particles performed as passivation ligands. ${ }^{10}$ Laser ablation has numerous points of interest; for example, effortlessness. Different types of nanostructures can be prepared through this technique, but this method requires a high amount of carbon matter for the development of carbon targets. Laser irradiation develops the different sized CNPs; large particles are effortlessly disposed of during the centrifugation process, so the resulting CNPs posses low yield, and the use proficiency of carbon matter was also less." Carbon particles can also be fabricated in ethanol via the laser ablation technique. ${ }^{15}$

\section{Electrochemical method}

Lu et al. ${ }^{16}$ used high-purity rods of graphite and profoundly situated pyrolytic graphite was used as an anode, with a partition of $2 \mathrm{~cm}$, platinum wire as a counter electrode, followed by their installation into ionic fluid/water solution. The exfoliation of carbon matter was initiated by the application of static potentials. The process of exfoliation was conducted due to the complex exchange of anionic intercalation from the ionic fluid and anodic oxidative cleavage of water. Until the $\mathrm{pH}$ of exfoliation products was neutral, they were washed with ethanol and water. After separation by filtration and ultracentrifugation at $15,000 \mathrm{rpm}$ at $20{ }^{\circ} \mathrm{C}$, C-dots of $6-8 \mathrm{~nm}$ size were obtained with the QY of $2.8-5.2 \%$. Yao et al. ${ }^{17}$ settled an anode of spectrum-pure graphite ring and a cathode of a titanium tube at the middle of the electrolyzer. An insulated O-ring was used to separate the cathode and anode. Sterilized water was used for an electrolyte medium. Ultrasonic power and electrolytic voltage were applied at one time, and pure blue fluorescent $\mathrm{C}$-dots of 2-3 nm size were quickly produced without any complex purification. The QY of the obtained C-dots was found as $8.9 \%$. The resultant $\mathrm{C}$-dots possessed a magnificent fluorescence effect and thermodynamic stability in aqueous solution." The extent of $\mathrm{C}$-dots can be managed by changing the current density. Larger $\mathrm{C}$-dots with longer emission wavelength can be formed by lowering the current density. ${ }^{10}$ Photoluminescent $\mathrm{C}$-dots $3 \mathrm{~nm}$ in size are specifically 
manufactured by electrochemical stunning of multi-walled carbon nanotubes. ${ }^{2}$ Water-soluble C-dots can also be prepared by the chemical oxidation treatment of flour. ${ }^{18}$

\section{Bottom-up approaches}

\section{Thermal routes}

For the preparation of C-dots, the burning sediment of candles was used as a starting material. The treatment of sediment with an oxidant, for example, $\mathrm{HNO}_{3}$ and $\mathrm{H}_{2} \mathrm{O}_{2} / \mathrm{AcOH}$, resulted in the formation of $\mathrm{C}$-dots. Polyacrylamide gel electrophoresis was conducted to isolate the obtained $\mathrm{C}$-dots and demonstrated that $\mathrm{C}$-dots with higher versatility possessed $\mathrm{PL}$ at shorter emission wavelengths. The QY estimations of the C-dots extended from $0.8 \%$ up to $1.9 \%$. Sediment from natural gas was treated with $\mathrm{HNO}_{3}$, followed by neutralization with $\mathrm{NaHCO}_{3}$. Finally, purification was achieved through dialysis, which prompted the development of photoluminescent C-dots. Metal nanostructures were formed on the surface of $\mathrm{C}$-dots by adding metal salts separately, including $\left.\mathrm{AgNO}_{3}, \mathrm{Cu}_{\left(\mathrm{NO}_{3}\right.}\right)_{2}$, and $\mathrm{PdCl} 2$, to the $\mathrm{C}$-dots solution in the presence of a reducing agent (ascorbic acid). ${ }^{10}$ The soot-based method is easy and clear. ${ }^{19}$ However, the QY of the fluorescent CNPs is considerably less $(<0.1 \%)$ and has no valuable purpose. An enhanced soot-based technique has been developed for the production of fluorescent CNP of 2-6 $\mathrm{nm}$ size and QY around $3 \%$. There are 3 discrete improvements in the accompanying adjusted method. Initially, a basic isolation method for a small-sized fluorescent molecule from heterogeneous particle mixture is developed. The technique is appropriate for the synthesis of these particles (on milligram scale). The second method demonstrates that large particles are less fluorescent than smaller ones and hence isolation of small molecules enhances the QY ( $<0.1 \%$ to $~ 3 \%)$ because they are more fluorescent. The third technique states that particles that are small in size enter cells with no further functionalization and the fluorescence property of the molecules may be used for cell imaging applications based on fluorescence..$^{19}$ Sootbased methods produce particle mixtures of various colors and isolation of these various colored particles is difficult by gel electrophoresis. ${ }^{19}$

\section{Microwave-assisted method}

Guan et al. ${ }^{20}$ investigated this method for the development of luminescent $\mathrm{C}$-dots with folic acid molecules as both nitrogen and carbon sources. Initially, a blend was formulated by dissolving folic acid $(15 \mathrm{mg}$ ) in $3 \mathrm{~mL}$ diethylene glycol, and this blend was placed in a domestic microwave oven of 750 $\mathrm{W}$ and heated for $40 \mathrm{~s}$. A red-brown-colored suspension was obtained and its dialysis was carried for 3 days against pure water. Luminescent NPs of carbon nitride developed after post treatment, with a size range around $4.51 \mathrm{~nm}$. Under activation at $360 \mathrm{~nm}$, the QY of carbon nitride NPs was found as 18.9\%. Even when the emission peak was excited at various wavelengths (from $320 \mathrm{~nm}$ to $420 \mathrm{~nm}$ ), its position remained about constant (at $460 \mathrm{~nm}$ ). Wang et al. ${ }^{21}$ introduced an easy onestage microwave-assisted method to formulate water-solvent phosphorus-containing C-dots. In this method, a mixture of 2
$\mathrm{mL}$ phytic acid $(70 \%)$ and $1 \mathrm{~mL}$ ethylenediamine was prepared with $25 \mathrm{~mL}$ ultrapure water, and the resulting turbid mixture was heated for around $8 \mathrm{~min}$ in a microwave oven of $700 \mathrm{~W}$. The purification of the crude substance resulted in the development of phosphorus-containing C-dots, also the aromatic structures of these C-dots were covalently attached to phosphorus groups. The phosphorus-containing $\mathrm{C}$-dots indicated two peak emissions when activated at low wavelengths, whereas a single peak was indicated at $525 \mathrm{~nm}$ (green fluorescence) by the NPs when activated at high wavelengths $(360-460 \mathrm{~nm}$ ). The QY of the subsequent phosphorus-containing C-dots was $21.65 \% .{ }^{11}$ In comparison with other approaches, the microwaveassisted method is more convenient and rapidly heats the carbon precursors. This method also simplifies the synthesis process, so the $\mathrm{C}$-dots are readily obtained within a few $\mathrm{min}$ with improved QY!" Another approach to develop CQDs under this method involves the heating of transparent aqueous solution of $P E G_{200}$ and saccharides in a microwave oven working at $500 \mathrm{~W}$ for 2-10 min. When the resultant $\mathrm{C}$-dots are activated at wavelengths extending from 330 to $460 \mathrm{~nm}$, they demonstrate interesting $\lambda$ ex-subordinate $\mathrm{PL}$ properties. The QY of the C-dots extended from 3.1\% to 6.3\%. Likewise, C-dots were developed by treating glucose with alkaline (or acidic solution) under ultrasonication for 4 hours. The PL emission of the $\mathrm{C}$-dots covered the whole visible to near-infrared (NIR) spectral region. The $\mathrm{C}$-dots had up-change $\mathrm{PL}$ properties when activated at $700-1000 \mathrm{~nm}$, demonstrating outflow in the wavelength range of $450-750 \mathrm{~nm} .{ }^{10}$

\section{The hydrothermal and aqueous-based method}

In order to develop PL C-dots, used coffee beans were exposed to the hydrothermal treatment. Before grinding into fine powder, used coffee beans were kept in an oven for drying. Later, it was autoclaved and calcined in air at $300{ }^{\circ} \mathrm{C}$ for $2 \mathrm{~h}$. C-dots were prepared through four successive stages:

- Dehydration,

- Polymerization,

- Carbonization, and

- Passivation.

Likewise, a green method was conducted to develop C-dots from used green tea leaves at $300{ }^{\circ} \mathrm{C}$ for $2 \mathrm{~h}$. The subsequent dark carbonized powder was resuspended in sterile water and later, dialysis was conducted to purify the $\mathrm{C}$-dots. In the development and passivation of $\mathrm{C}$-dots, the rich catechins present in green tea likely played a key role. Four unique molecules [cadaverine, glycine, ethylene diamine-tetra acetic acid (EDTA) 2-amino2-hydroxymethyl-propane-1,3-diol (TRIS)] comprising either a carboxyl group or an ether group or both in aqueous solvent were independently calcined hydrothermally at $300{ }^{\circ} \mathrm{C}$ for $2 \mathrm{~h}$. The outcome revealed that agents with both carboxyl and amino groups were beneficial for the development of highly waterdiffusible and photo luminescent $\mathrm{C}$-dots.

Furthermore, in a nitrogen atmosphere, EDTA was used to form $\mathrm{C}$-dots at $400{ }^{\circ} \mathrm{C}$ for $2 \mathrm{~h}$. A few EDTA precursors were not entirely degraded, which were then employed to prepare C-dots, 
prompting enhanced hydrophilicity. EDTA containing either a carboxylic group or an amino group or containing both in an aqueous solution were individually calcined hydrothermally for $2 \mathrm{~h}$ at $300{ }^{\circ} \mathrm{C}$. The results showed that precursors that contain both groups i.e. a carboxyl group and an amino group, were beneficial for photoluminescent and highly water-dispersible C-dots.

To develop organosilane-functionalized C-dots, (3-aminopropyl) trimethoxysilane was used as a precursor at $300{ }^{\circ} \mathrm{C}$ for $2 \mathrm{~h}$, in the absence of an additional passivating agent. Likewise, 4-aminoantipyrine and ammonium citrate was taken as another carbon precursor to develop C-dots in air at $300{ }^{\circ} \mathrm{C}$ for $2 \mathrm{~h}$. Various organic ammonium species were attached through a covalent bond to the surface, which served as a surface modifier, and altered the hydrophilic nature. ${ }^{10} \mathrm{~A}$ another approach under this method for the development of C-dots, various carbohydrates such as sucrose, glucose, and starch were used in the presence of strong acids such as $\mathrm{H}_{2} \mathrm{SO}_{4}$ as a starting material. These solutions were further treated with nitric acid and a carboxyl group was introduced on their surfaces to develop a class of carbon nanomaterials, which include C-dots. For further enhancement of their PL intensity, surface passivation with organic molecules and polymers was required.10 Development of CQDs with glucose as a precursor is easy and simple through a hydrothermal process. To increase the fluorescence emission, ethylene diamine can be used as a passivated agent. ${ }^{22}$

\section{Template method}

This approach has also been used for the preparation of nanosized C-dots. This approach contains two stages:

- Developing C-dots through calcination in the appropriate mesoporous silicon spheres or template, and

- Etching to erase supports and create nano-sized C-dots.

Zong et al. ${ }^{23}$ concluded a technique for the use of mesoporous spheres of silica as hard templates. These spheres of silica were saturated with a blended solution of citric acid and complex salts. After mesoporous supports were calcinated and expelled, the photostability of succeeding $\mathrm{C}$-dots along with mono-dispersion demonstrated fabulous luminescence properties. Yang et al. ${ }^{24}$ reported a method for developing uniformly morphologic PL C-dots using a soft-hard template approach. Copolymer Pluronic P123 was used in this approach as a soft template, while a hard template requested was mesoporous silica, various organic molecules such as diamine benzene, 1,3,5-trimethylbenzene were sources of carbon. After template removal, passivation, and carbonization, the obtained C-dots' compositions, tunable sizes, and crystalline degrees had additional high stability properties, up-conversion PL and PL effectiveness as high as 3.3-4.7\%. The difficulty of aggregate formation was successfully eliminated

Table 1. Properties of different synthetic methods

\begin{tabular}{|c|c|c|c|c|c|}
\hline S no & Synthetic methods & Size range & Quantum yield & Advantages & Disadvantages \\
\hline 1 & $\begin{array}{l}\text { Arc discharge } \\
\text { method }\end{array}$ & --- & - & Most attainable method & $\begin{array}{l}\text { Harsh conditions, possess low QY } \\
\text { and composite method }\end{array}$ \\
\hline 2 & $\begin{array}{l}\text { Laser ablation } \\
\text { method }\end{array}$ & $5 \mathrm{~nm}$ & $\begin{array}{l}\text { QY ranges between } \\
4 \%-10 \%\end{array}$ & $\begin{array}{l}\text { Effortlessness, effective technique, } \\
\text { different sized nanoparticles can be } \\
\text { prepared }\end{array}$ & $\begin{array}{l}\text { Large amount of carbon matter is } \\
\text { required, poor control over sizes, } \\
\text { low QY }\end{array}$ \\
\hline 3 & $\begin{array}{l}\text { Electrochemical } \\
\text { method }\end{array}$ & $6-8 \mathrm{~nm}$ & $\begin{array}{l}\text { QY ranges between } \\
2.8 \%-8.9 \%\end{array}$ & $\begin{array}{l}\text { Stable method, extent of carbon dots } \\
\text { can be managed by changing current } \\
\text { density, water-soluble carbon dot can } \\
\text { also be prepared }\end{array}$ & Complex method \\
\hline 4 & Thermal route & $2-6 \mathrm{~nm}$ & $\begin{array}{l}\text { QY ranges between } \\
0.1 \%-3 \%\end{array}$ & $\begin{array}{l}\text { Easy and straightforward method, } \\
\text { have fluorescence property, } \\
\text { appropriate method for particles (on } \\
\text { milligram scale) }\end{array}$ & Low QY \\
\hline 5 & $\begin{array}{l}\text { Microwave- } \\
\text { assisted method }\end{array}$ & $4.51 \mathrm{~nm}$ & $\begin{array}{l}\text { The PL QY and } \\
\text { phosphorus } \\
\text { containing QY ranges } \\
\text { between } 3.1 \% \text { - } \\
6.3 \% \text { and } 21.65 \% \\
\text { respectively }\end{array}$ & $\begin{array}{l}\text { Simple and convenient method, } \\
\text { inexpensive and eco-friendly method }\end{array}$ & Poor control over sizes \\
\hline 6 & $\begin{array}{l}\text { Hydrothermal and } \\
\text { aqueous-based } \\
\text { method }\end{array}$ & - & - & $\begin{array}{l}\text { Highly water-dispersible carbon } \\
\text { dots can be prepared, inexpensive, } \\
\text { non-toxic }\end{array}$ & Poor control over sizes \\
\hline 7 & Template method & - & - & $\begin{array}{l}\text { Carbon dots have biocompatibility } \\
\text { and colloidal stability }\end{array}$ & $\begin{array}{l}\text { Time-consuming and expensive } \\
\text { method, have limited QY }\end{array}$ \\
\hline
\end{tabular}

QY: Quantum yield, PL: Photoluminescence 
through this soft-hard template approach, and the development of $\mathrm{C}$-dots was permitted with a narrow distribution of size due to confinement of size. Lai et al. ${ }^{25}$ developed $\mathrm{C}$-dots in the NPs of mesoporous silica, which served as a nanoreactor to control the size distribution. Initially the authors developed mesoporous silica NPs $\left(\mathrm{mSiO}_{2}\right)$; the $\mathrm{mSiO}_{2} \mathrm{NPs}$ were blended with PEG$\mathrm{NH}_{2}$ and glycerol, then heated to $30 \mathrm{~min}$ at $230{ }^{\circ} \mathrm{C}$. Finally, the extraction of crude items was achieved through centrifugation to acquire the $\mathrm{C}$-dot nano-composites without scratching. Simultaneously capping PEG onto the surface of $\mathrm{mSiO}_{2}$, the subsequent C-dots indicated additional improvement in QY, biocompatibility, and colloidal stability. During the synthetic process of $\mathrm{C}$-dots, corrosive acid or base was expected to etch the template because the formation of mesoporous silica was difficult. This strategy was time consuming and expensive. Moreover, the template was hard to be etched off completely due to the high-temperature pyrolysis of the template, also the process of separation and purification was difficult, and the QY was limited."1 The properties of the different synthetic methods are summarized in Table 1.

\section{Characterization of carbon quantum dots}

Keeping in mind the goal to attain information about the synthetic properties of $\mathrm{C}$-dots, numerous techniques may be used in order to characterize $\mathrm{C}$-dots, for example, nuclear magnetic resonance (NMR), X-ray diffraction (XRD), transmission electron microscope (TEM), fourier-transform infrared spectroscopy (FTIR), ultraviolet (UV) spectroscopy, and PL.11

\section{TEM}

TEM can be used to identify the ultrastructure of samples because it possesses a high resolution of 0.1-0.2 $\mathrm{nm}$. TEM hasa wide demand in science, pharmaceuticals, material science, and other research and development departments. The morphology of NPs can be studied by this technique, in order to understand information regarding their shape, size, and dispersion. TEM is broadly used as a part of the characterization of C-dots. To determine the fine structure of $\mathrm{C}$-dots, high-resolution TEM can also be used. The crystalline nature of $\mathrm{C}$-dots can be classified into two types of lattice fringes, named as interlayer spacing and in-plane lattice spacing, respectively. Interlayer spacing typically is focused at around $0.34 \mathrm{~nm}$, whereas in-plane lattice spacing is focused at $0.24 \mathrm{~nm} .^{11}$ Zhang et al. ${ }^{26}$ carried out acid oxidation of graphite in order to synthesize $\mathrm{C}$-dots and their lattice spacing was generally less than $0.3 \mathrm{~nm}$, demonstrating that the large portion of $\mathrm{C}$-dots were actually separate graphenes. Shinde and Pillai ${ }^{27}$ synthesized C-dots from multiwalled carbon nanotube dots by means of an electrochemical technique, and at the same time, two kinds of lattice fringes were observed in the high-resolution TEM image."1

\section{$X R D$}

$X R D$ is efficiently used to characterize C-dots and to obtain information of particle size, phase purity, and crystal structure.11,28 XRD also determines the crystalline phases of CQDs. ${ }^{29}$ Liu et al. $^{30}$ synthesized $\mathrm{C}$-dots by using hexaperihexabenzocoronene as the precursor. C-dots with a size of $\sim 60 \mathrm{~nm}$ in breadth and 2-3 $\mathrm{nm}$ thickness were produced, after pyrolysis at high temperature, surface functionalization, reduction treatment, and oxidative peeling. The so obtained C-dots possessed a fluorescence QY of $3.8 \%$. Mao et al. ${ }^{31}$ developed photoluminescent $\mathrm{C}$-dots with glycerol through a one-stage pyrolysis of poly (acrylic acid). The various structures and optical features of the $\mathrm{C}$-dots were altogether examined. The XRD design demonstrated a wide peak near $2 \theta=24^{\circ}$, further affirming the white fluorescent $C$-dots' graphite structure. Bourlinos et al. $^{2}$ synthesized $\mathrm{C}$-dots through the calcination of ammonium citrate salt at $300{ }^{\circ} \mathrm{C}$; the relating XRD design showed two reflections that were superimposed, which confirmed the presence of exceptional carbon alkyl groups that were surface modified. ${ }^{11}$

\section{FTIR}

For the determination of functional groups that are present on the surface of $\mathrm{C}$-dots, eFTIR has also been used. ${ }^{10} \mathrm{C}$-dots mostly comprise oxygen, carbon, and hydrogen. Due to the development of $\mathrm{C}$-dots by the partial oxidation of a carbon precursor, carboxyl or carboxylic acid groups, hydroxyl groups, and ether/epoxy are abundant on the surface of $\mathrm{C}$-dots and so for the investigation of these groups containing oxygen, FTIR is a useful device. Before applying, changes were required to be made with $\mathrm{C}$-dots for balancing out potential wells on the energy surface, lesser cytotoxicity, and higher fluorescence QY. Altered C-dots can be characterized using infrared spectroscopy so as to decide if they are passivated adequately. Peng et al. ${ }^{32}$ developed C-dots of size 1-4 $\mathrm{nm}$ through the compound oxidation of carbon strands of one micron, 1-4 nm C-dots, the particles so formed broke up in a polar solvent and were soluble in water; dimethyl sulfoxide and dimethyl formamide being examples. The infrared range of these was recorded. Peaks of characteristic absorption at 1724 $\mathrm{cm}^{-1}$ and $3307 \mathrm{~cm}^{-1}$ proposed carboxyl groups' appearance on their surface; the presence of a double bond was shown by the peak of absorption at $1579 \mathrm{~cm}^{-1}$, and the presence of ether linkage was implied by an absorption peak at $1097 \mathrm{~cm}^{-1}$.

\section{NMR}

An NMR strategy is often used to obtain structural information of $\mathrm{C}$-dots. Hybrid tpes of $\mathrm{C}$-atoms in the crystalline network and binding mode between carbon atoms is determined by NMR. Tian et al. ${ }^{33}$ used natural gas burning sediment as a carbon source and conducted the refluxing with nitric acid, which resulted in the development of $\mathrm{C}$-dots. Aromatic $\left(\mathrm{sp}^{2}\right)$ carbons show resonance in the region extending from 90-180 ppm, whereas aliphatic $\left(\mathrm{sp}^{3}\right)$ carbons show resonance in the region extending from 8-80 ppm, structural insights of $\mathrm{C}$-dots is determined with the help of NMR measurements by distinguishing $\mathrm{sp}^{3}$ carbons from those of $\mathrm{sp}^{2}$. The absence of aliphatic carbons was indicated by a carbon-13 (13C) NMR range, which depicted the absence of a single peak below 120 ppm. Within the region extending from 120-150 ppm, a sequence of peaks appeared and most of these peaks emerged from aromatic carbons. $13 \mathrm{C}$ NMR spectroscopic estimations affirmed that the $\mathrm{C}$-dots had developed from $\mathrm{sp}^{2}$ carbons." 


\section{UV spectroscopy}

Strong (UV) absorption is usually shown by C-dots prepared using various techniques, but still the positions of absorption peaks of UV are entirely different for different techniques used for the preparation of C-dots. ${ }^{12}$ C-dots of 3.8, 1.5-3, an $1.2 \mathrm{~nm}$ transmit at NIR, visible $(400-700 \mathrm{~nm})$, and $U V(350 \mathrm{~nm})$ regions, respectively. ${ }^{10} \mathrm{Li}$ et al. ${ }^{34}$ added active carbon $(4.0 \mathrm{~g})$ into $70 \mathrm{~mL}$ of hydrogen peroxide to make a suspension and sonicated it for 2 hours at room temperature. After filtration, fluorescent water-soluble $\mathrm{C}$-dots were obtained with a diameter range of 5-10 nm, and typical absorption of an aromatic pi framework was represented by the common UV-visible absorption band peak at 250-300 $\mathrm{nm}$. Wang et al. ${ }^{35}$ immediately added $0.5 \mathrm{~g}$ citrus extract anhydrous into $\mathrm{N}$-( $\beta$-aminoethyl)- $\gamma$-aminopropyl methyl dimethoxy silane solution with vigorous stirring at 240 ${ }^{\circ} \mathrm{C}$ and maintained the same for $1 \mathrm{~min}$. Amorphous CNPs of 0.9-nm diameter were incorporated; after natural cooling and purification, they were also very luminescent ( $Q Y=47 \%$ ). The C-dots thus manufactured had a strong UV-visible absorption peak at $360 \mathrm{~nm}$. Dong et al..$^{36}$ used carbonation of citrus acid to form photoluminescent $\mathrm{C}$-dots at $200{ }^{\circ} \mathrm{C}$. Their $\mathrm{C}$-dots were nanosheets of 0.5-2.0-nm thickness and $15 \mathrm{~nm}$ in width, demonstrating UV absorption at $362 \mathrm{~nm}$ in the absorption range, the NPs were consistent in size and this was evident by the narrow peak width. The maximum emission wavelength remained unaltered at a point when activated at various excitation wavelengths. Tang et al. ${ }^{37}$ conducted pyrolysis of a glucose solution assisted by microwave for the preparation of C-dots; the diameter of the obtained C-dots was $1.65 \mathrm{~nm}$ with a fluorescence QY of 7-10\%. Two evident UV absorption peaks at 228 and $282 \mathrm{~nm}$ were indicated by the aqueous solution of these C-dots. The intensity of both UV absorption peaks was increased by extending the microwave heating time, whereas the peak positions remained unaltered and showed no connection with NPs size."1

$P L$

As another class of nanomaterials, C-dots have elicited remarkable consideration in the past decade. From an essential perspective to property and application, $\mathrm{PL}$ is the most intriguing characterization of $\mathrm{C}$-dots. C-dots possess certain optical properties that may reflect impacts from particles of various sizes in the sample. In addition to this, various emissive sites are distributed on each $\mathrm{C}$-dot. However, investigations on the optical properties of small-sized $\mathrm{C}$-dots are dubious because the accurate mechanism of $\mathrm{PL}$ is unclear. One exceptional feature of the PL of $\mathrm{C}$-dots is the clear $\lambda$ ex-dependence of the emission wavelength and intensity. By using surfactantmodified silica spheres as carriers and resols as carbon precursors, C-dots of 1.5 2.5 nm were synthesized followed by surface passivation with PEG1500N. The resulting QY of passivated $\mathrm{C}$-dots was characterized as $14.7 \%$. A suspension of passivated $\mathrm{C}$-dots showed strong blue luminescence when excited at $365 \mathrm{~nm}$. These $C$-dots have broad emission spectra, extending from 430 to $580 \mathrm{~nm}$, and they exhibit $\lambda$-exdependent $\mathrm{PL}$ emission. Brilliant and vibrant PL of $\mathrm{C}$-dots can be ascribed to the presence of a surface energy trap settled by surface passivation.11

\section{Biodistribution and pharmacokinetics}

Subcutaneous (s.c.) and intravenous (i.v.) injections are the basic routes of administration of CQDs. As these QDs reach the systematic circulation, they identify the target and bind to it. After attaching to the target, light is emitted by each QD. The color of the fluorescence depends on the size of the QD and can be easily detected and identified by various techniques. CQDs or C-dots, are small semiconductor nanocrystals of 1-10 nanometers obtained with different surface passivation processes either by modification or functionalization. These have very low toxicity and high fluorescence, and thus have numerous applications in bioanalysis, bioimaging, drug delivery, and other related areas. Accordingly, it is necessary to consider the biosafety studies of $\mathrm{C}$-dots, which includes biodistribution and pharmacokinetics. In 2009, Yang et al. ${ }^{38}$ were the first to investigate the biodistribution pattern of $\mathrm{C}$-dots by combining $13 \mathrm{C}$ labeling and whole-body imaging. The biodistribution and translocation of $\mathrm{C}$-dots in mice were concluded. It was found that $\mathrm{C}$-dots could not cross the blood brain barrier, but could easily distribute into the whole body. In certain organs such as the spleen, liver, and kidneys, moderate accumulation was observed. . $^{39,40}$

Likewise, Yang et al. ${ }^{38}$ and Tao et al. ${ }^{39}$ conducted toxicity and biodistribution studies by labeling C-dots using ${ }^{125}$. Pharmacokinetic analysis of $\mathrm{C}$-dots was performed using a two-compartment model. The distribution $\mathrm{t}_{1 / 2}$ of $\mathrm{C}$-dots was 0.1 $\mathrm{h}$ and the clearance half-life was $2.1 \mathrm{~h}$. The distribution pattern of C-dots was similar to that of Yang et al.'s ${ }^{38}$ as moderate accumulation was observed in the spleen, liver, kidney, but not the brain. Biodistribution studies of $\mathrm{C}$-dots were also carried out by Li et al. ${ }^{34}$ in mice using i.v. injections. Imaging of dissected and sliced organs was performed under $405 \mathrm{~nm}$ excitation and $500 \mathrm{~nm}$ emission. Blue fluorescence was detected in different body organs including the spleen, liver, heart, kidney, lungs, small intestine, and brain. High concentrations of $\mathrm{C}$-dots were noticed in the spleen. In other exposure pathways, due to high hydrophilicity and small size, C-dots exhibited free translocation in the body. The biodistribution of Gd-carbon dots was investigated by $\mathrm{Xu}$ et al. ${ }^{41}$ after intra-tracheal instillation. $\mathrm{Gd}^{3+}$ quantification was performed so as to measure the biodistribution of QD. Accumulation of QD in liver, kidney, lungs, heart, and spleen was reported. Tumor-bearing mice had almost the same distribution with an accumulation of $10 \%$ injected dose per gram of tissue $\left(\mathrm{ID} \mathrm{g}^{-1}\right)$ in the tumor. The authors stated that $\mathrm{C}$-dots could freely translocate as well as distribute in different organs of the body. ${ }^{42}$

\section{Cytotoxicity}

The ability of certain chemicals or mediator cells to destroy living cells is known as cytotoxicity. These mediators or chemicals can induce necrosis (accidental cell death) or apoptosis (programmed cell death) in healthy living cells of humans and animals. C-dots have been considered as possible replacements for organic dyes and metallic quantum in bioimaging due to their chemical stability, broad excitation 
ranges, and excellent fluorescence properties. Biocompatibility is considered important for their application in cell labeling and imaging thus making them the most important property of QD. The toxicity of $\mathrm{C}$-dots is a basic concern. Studies related to cytotoxicity of $\mathrm{C}$-dots have been conducted by different scientists, organizations, and institutes, but only a few results and reports are present right now. Zhang et al. ${ }^{18}$ investigated the cytotoxicity of carbon QDs on rat mesangial cells. No apparent cytotoxicity and much better biosafety properties of $\mathrm{C}$-dots were reported for biologic fluorescent probe applications. Fluorescent $\mathrm{C}$-dots were synthesized and evaluated for cytotoxicity. ${ }^{19}$ Various indicators such as cell viability, malondialdehyde, total reactive oxygen species (ROS), glutathione, and lactate dehydrogenase were evaluated using a human bronchial epithelial (16HBE) cell line. The results showed that $\mathrm{C}$-dots significantly increased the membrane permeability of $16 \mathrm{HBE}$ cells. C-dots induce oxidative stress, which exhausts the antioxidant defenses of cells, leading to decreased cell viability. Therefore, surface modification of C-dots could minimize their cytotoxicity.

Sun et al. ${ }^{14}$ conducted in vitro and in vivo cytotoxicity studies of C-dots. Viability, proliferation, and cell mortality of MCF-7 cells (human breast cells) and HT-29 cells (human colorectal adenocarcinoma) were determined by conducting trypan blue and methylthiazole tetrazolium assays after exposing them to C-dots. C-dots thus used were synthesized using PEG1500N laser ablation and surface passivation techniques. C-dots as agents have been employed for in vivo testing in mice. They give a bright fluorescent appearance in solution form. No acute toxicologic response was reported when $\mathrm{C}$-dots solutions were injected i.v. in mice. These $\mathrm{C}$-dots were excreted primarily via urine within $\sim 3 \mathrm{~h}$ of injection, ${ }^{38}$ thus signifying the nontoxic nature of $\mathrm{C}$-dots. Fluorescence of $\mathrm{C}$-dots in the liver and kidney can be observed after $4 \mathrm{~h}$ of i.v. injection. High accumulation of carbon dots leads to higher fluorescence in the kidney as compared with that in the liver. Urine being the chief excretion pathway of C-dots, also leads to higher fluorescence. No toxicity was reported when $\mathrm{C}$-dots were administered i.v. in male CD-1 mice. Even exposure of $\mathrm{C}$-dots for 28 days showed no toxic effects. ${ }^{38}$ All of the above experiments led to the conclusion that $\mathrm{C}$-dots have extensive adequacy for in vivo and in vitro bioimaging and drug delivery studies. Different research has suggested that $\mathrm{C}$-dots will have biocompatibility almost equivalent to that of United States Food and Drug Administration-approved organic dyes used in optical imaging e.g., indocyanine green. Although more cytotoxicity studies of C-dots are needed, the data above suggest a bright future for C-dots in drug delivery and bioimaging studies.

\section{Biomedical applications}

\section{Bioimaging}

CQDs play an important role in biomedical applications; bioimaging is one of the essential applications, which can be defined as the process in which images of living organisms are produced with the help of techniques such as magnetic resonance imaging $(\mathrm{MRI}), \mathrm{X}$-rays, and ultrasound. It is also used to determine three dimensional structural information. ${ }^{43}$ CQDs have numerous advantages over semiconductor QDs because of their biocompatibility, low toxicity, and strong PL. These properties make CQDs very advantageous in the visualization of biologic systems both in vivo and in vitro. This is important to know that CQDs in themselves are nontoxic, but it is the passivating agent on the surface of CQDs that is mainly responsible for the cytotoxicity. Surface passivating agents with low toxicity can be safely used for in vivo imaging at higher concentrations. For example, in toxicity evaluations, when PEGylated CQDs were introduced i.v. (8-40 $\mathrm{mg} \mathrm{kg}^{-1}$ CQD/body weight) into mice for up to 28 days, no significant in vivo toxic effects were observed. When mice were exposed to various doses of $\mathrm{CQDs}$ and $\mathrm{NaCl}$ control, all physiologic indicators were at the same levels. Therefore, at various exposure levels, CQDs indicated non-toxicity at durations beyond those that can be used for in vivo imaging studies. ${ }^{44}$ CQDs also possess the fluorescence property with biocompatibility and low biotoxicity. This fluorescence property of CQDs makes them potential candidates for fluorescence bioimaging and multimodal bioimaging both in vivo and in vitro. For example, a PEGylated CQD was labeled on E. coli ATCC25922 and confocal microscopy images were produced at different excitation wavelengths. It was demonstrated that the CQD could be used as a fluorescence contrast agent in mice. An aqueous solution of PEGylated CQDs was injected s.c. into mice and at various excitation wavelengths and fluorescence images were obtained. A noticeable contrast was observed for imaging in both green and red emissions. Similar results were obtained when a similar experiment was conducted on nude mice. More precisely, fluorescence imaging was performed with excitation at various wavelengths ranging from $455 \mathrm{~nm}$ to $704 \mathrm{~nm}$ along with a s.c. introduction of an aqueous solution of CQD into mice. Excitation at $595 \mathrm{~nm}$ showed the best fluorescence contrast.

Another property is multimodal bioimaging, which can be defined as the combination of optical imaging and MRI modalities. MRI demonstrates high spatial resolution and the potential to obtain anatomic and physiologic information. On the other hand, rapid screening was determined by optical imaging. For example, for multi-modality bioimaging, iron oxide-doped CQDs (IO-CQDS) were fabricated. Organic precursors with small $\mathrm{Fe}_{3} \mathrm{O}_{4} \mathrm{NPs}$ (approximate size $6 \mathrm{~nm}$ ) were thermally decomposed, which led to the formation of IO-CQDS. i.v. injections of IO-CQDS were administered to rats for in vivo bioimaging and fluorescence signals appeared in spleen slide samples. The combination of various imaging technologies with the fluorescent imaging of CQDs is also beneficial due to the biocompatibility of CQDs. ${ }^{12}$ Loading CQDs with enzyme-responsive mesoporous silica nanocarriers with a $\mathrm{pH}$-switchable zwitterionic surface can be used for targeted imaging and drug delivery to tumors. ${ }^{45}$

\section{Targeted drug delivery}

CQDs are one of the most effective carbon-based materials that can be used for various biologic applications due to their biocompatibility. The insignificant cytotoxicity of CQDs makes them potential candidates for safe, effective, and targeted 
delivery. CQDs are attractive candidates for theranostic agents, which can be defined as agents that have both therapeutic and diagnostic capabilities. For example, a multifunctional theranostic agent (CD-Oxa) was developed when the surfaces of $\mathrm{C}$-dots containing amine groups were conjugated with an anticancer agent [oxidized oxaliplatin, oxa (IV)-COOH]. CDOxa profitably combines the therapeutic properties of Oxa and the optical properties of C-dots. They possess better biocompatibility, bioimaging features, and anticancer effects for in vitro studies. The in vivo study reveals that distribution of drug can be followed by monitoring the fluorescence signal of CD-Oxa, which assists to customize the dose of medicament along with the injection time. To deliver the DNA to cells, an assembly was prepared by coupling CQDs with gold NPs, followed by conjugation with PEI-pDNA. The experimental study revealed that there was a possible delivery of cells with the aid of CQDs. Delivery of doxorubicinorubicin (anti-cancer) in a multimodality fashion can be possible with the use of CQDfunctionalized gold nanorods. Under physiologic and HixsonCrowell standard conditions, haloperidol (anti-psychotic) grafted CQDs with cysteamine hydrochloride can be used for controlled release for up to $40 \mathrm{~h}$. In addition to bioimaging, conjugation of ciprofloxacin (a broad spectrum antibiotic) with CQDs under physiologic conditions also gave an efficient new nanocarrier for controlled drug release..$^{12,44,45}$

\section{Nanomedicine}

CQDs, being small fluorescent NPs, serve as a better alternative to other fluorescent nanomaterials. CQDs have an appreciable application in nanomedicine because they do not cause any kind of toxicity in animals. In an experiment, CQDs were injected i.v. in mice and an evaluation was conducted after 4 weeks, which concluded that there was no significant effect on organs and their internal functions. Their insignificant effect and low cytotoxicity level allow them to be used for in vivo studies. In plasma samples, highly biocompatible CQDs supported by prothrombin time assays concluded that CQDs did not affect thrombin activity. Also, they did not lead to coagulation of the blood. CQDs have an attractive application in photodynamic therapy (therapy that uses special drugs that activate by light for the treatment of superficial tumors). Cancer cells MCF-7 and MDA-MB-231 are effectively inhibited by CQDs. In addition, CQDs are promising photosensitizers because they are able to produce ROS and the selective localization of CQDs into tumors makes them suitable candidates for photosensitization.

Route of administration and surface coating are both factors that influence the circulation and uptake of CQDs. There is rapid and effective excretion of CQDs from the body when they are administered through the parental route (i.v., intramuscular and s.c. injection). In photodynamic therapy, the up-conversion property of CQDs plays an important role in the treatment of deep-seated tumors; conjugation of CQDs with protoporphyrin IX (a conventional photosensitizer) followed by the indirect excitation ( $800 \mathrm{~nm}$ ) of photosensitizer via Forster/ fluorescence resonance energy transfer (FRET). Excitation at $800 \mathrm{~nm}$ comes under the phototherapeutic window and is able to penetrate four times deeper into human tissue as compared with excitation with light at $630 \mathrm{~nm}$, which has been used in clinical photodynamic therapy. CQDs also play a significant role in radiotherapy; the coating of a silver shell (C-Ag-PEG CQDs) on PEG-CQDs makes them accessible to be used as radiosensitizers in Du145 cells. The availability of CQDs as nanocarriers makes them efficient for tracking and the delivery of genes or drugs, branched polyethylenimine CQDs possess considerable potential for gene delivery. CQDs also have an appreciable application in controlled drug release-controlled release of drug in HeLa cells can be achieved by loading CQDs with doxorubicin. However, it is not clear whether CQDs can specifically target a disease state, thus limiting their efficacy in therapeutic applications. $12,44,45$

\section{Biosensing}

CQDs have a wide application in biosensing. Certain properties of CQDs, such as high water solubility, surface modification flexibility, better cell permeation, low toxicity, and high biocompatibility make them potential biosensors. Cellulose, copper, glucose, nucleic acid, iron, potassium, an phosphate can be monitored visually with the aid of CQD-based biosensors. CQDs can be used as a successful fluorescent sensing agent for the detection of nucleic acid with a selective single-base mismatch. The idea involves the adsorption of fluorescentlylabeled single-stranded DNA (ssDNA) via CQDs by means of pi-pi association, which was accustomed by extensive fluorescence quenching, further hybridized with its target to consequence for the formation of double sDNA. As a result, it was observed that the SsDNA was desorbed from the surface of CQDs, which was accompanied by a successive revival of fluorescence, prying with the target DNA. Detection and imaging of mitochondrial $\mathrm{H}_{2} \mathrm{O}_{2}$ were verified by means of CQDbased FRET. CQDs fill in as a contributor of energy transfer and transporter for the sensing framework. Covalently-linked CQDs with an $\mathrm{H}_{2} \mathrm{O}_{2}$ recognition element, boronate-secured fluorescein can be used for the imaging of $\mathrm{H}_{2} \mathrm{O}_{2}$, which was endogenously produced in RAW 264.7 macrophage cells. ${ }^{12}$ The principle of FRET and homogenous assays was employed to develop an immunosensor for 4,4-dibrominated biphenyl (PBB15) detection-an organic pollutant that causes endocrine system disturbance. The immunosensor consists of antibodies of PBB15, functionalized with gold NPs (AuNP) that behave as the fluorescence acceptor, and PBB15 antigens labeled with carbon QDs, which behave as a fluorescence donor. FRET resulted that CQD fluorescence was efficiently quenched by means of AuNP. On adding PBB15 to the solution, competitive immunoreactions took place and antigens labeled with CQDs were unconfined from the surface of AuNP and resulted in fluorescence recovery. This particular immunosensor was used as a fine example for the immunoassay development to identify analytes with preferable antigens and antibodies. ${ }^{12,44,45}$ Vitamin $\mathrm{B}_{12}$-coated CQD serve as a radiometric nanosensor that exhibit an excellent selectivity for phenolic carbofuran. ${ }^{46}$ In addition to this, CQDs are used as a fluorescent probe for recognizing small bioanalytes (anti-bacterial drugs). An experimental study was conducted on such example, which involves the 
Table 2. Different applications of delivery systems

\begin{tabular}{|c|c|c|c|}
\hline S No & Delivery system & Applications & References \\
\hline 1 & Carboxylic functionalized CQD & For DNA detection and fabrication of DNA biosensor & 47 \\
\hline 2 & Photoluminscent CQD & For $\mathrm{Fe}^{3+}$ detection in biosystems as a biosensor reagent & 48 \\
\hline 3 & \multirow[b]{2}{*}{ CQD } & For multiphoton bioimaging & 49 \\
\hline 4 & & For optical bioimaging in vivo and in vitro & 50 \\
\hline 6 & CQD loaded with mesoporous silica nanocarriers & For targeted drug delivery and imaging to tumor & 45 \\
\hline 7 & \multirow{3}{*}{ Carbon nanotubes } & For treatment of tumors & 52 \\
\hline 8 & & For chemotherapeutic drug delivery & 52 \\
\hline 9 & & For in vivo cancer therapy as drug delivery agent & 52 \\
\hline
\end{tabular}

CQD: Carbon quantum dots

production of fluorescent N-CQDs from glutamic acid. These $\mathrm{N}-\mathrm{CQD}$ s were produced by a one-step pyrolysis technique. The resulting N-CQDs were further used for amoxicillin (antibacterial) detection. Other small bioanalytes such as ascorbic acid, dopamine, and glucose were also detected by CQDs. ${ }^{12,44,45}$

\section{Photocatalysis}

Recently, the process of photocatalysis has increased with colossal force as greener options in natural synthesis. Awareness in the photocatalytic process has been roused to some degree by the acknowledgment that sunlight is an adequate unlimited source of energy. Nonetheless, the elevated vitality of UV and short wavelength visible light can unfavorably harm natural compounds. The exhibited capacity of outfitting the extended wavelength light and vitality conversion with a CQD solution offers a fantastic opportunity for their use as photocatalysts in the natural synthetic process. A recent review has shown that CQDs in the range of $1-4 \mathrm{~nm}$ are powerful NIR lightdetermined photocatalysts for specifically oxidizing alcohols into benzaldehydes with great conversion proficiency (92\%) and specificity (100\%) because of their incredible catalytic action for $\mathrm{H}_{2} \mathrm{O}_{2}$ deterioration and NIR light-determined electron transfer activity. Doping of $171 \mathrm{CQDs}$ and fitting the surface groups can adequately modulate the photocatalytic activity of CQDs. In contrast, CQDs in the range of 5-10 nm combined via electrochemical removal of graphite indicated light-instigated proton features in solution form, which can serve as an acid catalyst for catalyzing a sequence of natural changes in watery mediums under visible light. As a standout amongst the most well-known photocatalysts, $\mathrm{TiO}_{2}$ has been used as a part of the expulsion of natural contaminations and for generating $\mathrm{H}_{2}$ via water splitting. However, a noteworthy downside in its photocatalytic proficiency dwells in its insufficient use of visible light as the illumination source. Just under $5 \%$ of sunlight is used by $\mathrm{TiO}_{2}$ because a bandgap of bulk $\mathrm{TiO}_{2}$ comes under the UV area (3.0-3.2 eV). Therefore, bandgap engineering through a conceivable change of $\mathrm{TiO}_{2}$-based media is one of the conceivable ways to deal with upgrading the execution of
$\mathrm{TiO}_{2}$ photocatalysts. In perspective of their appealing optical properties and up-change specifically, a nanocomposite of $\mathrm{TiO}_{2}$ and CQDs is required to understand the productive use of the full sunlight spectrum. By using methylene blue (MB) as the model agent, it has been demonstrated that nanocomposites of CQDs and $\mathrm{TiO}_{2}$ can totally deteriorate $\mathrm{MB}(50 \mathrm{mg} / \mathrm{mL})$ under visible light illumination in $25 \mathrm{~min}$, where just $0.5 \%$ of $\mathrm{MB}$ is debased when immaculate $\mathrm{TiO}_{2}$ is used as a photocatalyst. Apart from gathering visible light and changing it over to short wavelength light by up-transformation, which thusly energizes $\mathrm{TiO}_{2}$ to frame pairs of electron-hole, it is trusted that the nanocomposites of CQDs encourage the relocation of electrons from $\mathrm{TiO}_{2}$ and the electrons can carry unreservedly along the directing ways of the CQDs, permitting charge partition, adjustment and obstructing recombination, and accordingly creating extensive openings (holes) at the $\mathrm{TiO}_{2}$ surface. Long-lived openings then record for the greatly improved photocatalytic action of the $\mathrm{CQD}-\mathrm{TiO}_{2}$ nanocomposites. In a like manner, comparative conduct was seen with $\mathrm{TiO}_{2}-\mathrm{CQD}$ nanotube composites $\mathrm{TiO}_{2}$ CQD nanosheet nanocomposites and $\mathrm{TiO}_{2}-\mathrm{CQD}$ nanotube composites in the photocatalytic deterioration of rhodamine and MB respectively. 12,44,46 Different applications of various delivery systems are summarized in Table 2.

\section{CONCLUSIONS}

- In this review, we have elaborated the recent advancement in CQDs, emphasizing their synthesis methods and characterization, followed by their biomedical applications.

- The unique properties of CQDs are beneficial for potential applications in biomedical science and research.

- C-dots have extensive adequacy for in vivo and in vitro bioimaging and drug delivery studies.

- Because of their biocompatibility, low toxicity, strong PL, synthetic and photograph steadiness, C-dots have become a fascinating material for bioimaging and in the detection of different analytes. 


\section{ACKNOWLEDGEMENTS}

The authors gratefully acknowledge Dr. Madhu Chitkara (Vice Chancellor, Chitkara University, Rajpura, Punjab, India) and Dr. Sandeep Arora (Dean, Chitkara University, Rajpura, Punjab, India) for support and institutional facilities.

Conflict of interest: No conflict of interest was declared by the authors.

\section{REFERENCES}

1. Bradburne CE, Delehanty JB, Boeneman Gemmill K, Mei BC, Mattoussi H, Susumu K, Blanco-Canosa JB, Dawson PE, Medintz IL. Cytotoxicity of Quantum Dots used for in vitro cellular labeling: Role of QD surface ligand, delivery modality, cell type, and direct comparison to organic fluorophores. Bioconjug Chem. 2013;24:1570-1583.

2. Bourlinos AB, Stassinopoulos A, Anglos D, Zboril R, Karakassides M, Giannelis EP. Surface functionalized carbogenic Quantum Dots. Small. 2008;4:455-458.

3. Klostranec JM, Chan WCW. Quantum Dots in Biological and Biomedical Research: Recent Progress and Present Challenges. Adv Mater. 2006;18:1953-1964.

4. Modani S, Kharwade M, Nijhawan M. Quantum Dots: A novelty of medical field with multiple applications. Int J Curr Pharm Res. 2013;5:55-59.

5. Zhu JJ, Li JJ, Huang HP, Cheng FF. Quantum dots for DNA biosensing. Springer Briefs in Molecular Science. 2013:1-91.

6. Chen N, He Y, Su Y, Li X, Huang Q, Wang H, Zhang X, Tai R, Fan C. The cytotoxicity of cadmium-based quantum dots. Biomaterials. 2012;33:1238-1244.

7. Qi L, Gao X. Emerging application of Quantum Dots for drug delivery and therapy. Expert Opin Drug Deliv. 2008;5:263-267.

8. Tan L, Huang G, Liu T, Fu C, Zhou Y, Zhu Z, Meng X. Synthesis of highly bright oil-soluble Carbon Quantum Dots by hot-injection method with $\mathrm{N}$ and B co-doping. J Nanosci Nanotechnol. 2016;16:2652-2657.

9. Tope S, Saudagar S, Kale N, Khambayat S, Bhise K. Therapeutic application of Quantum Dot (QD). The Pharma Innovation. 2014;2:86-105.

10. Roy P, Chen PC, Periasamy AP, Chen YN, Chang HT. Photoluminescent carbon nanodots: Synthesis, physicochemical properties and analytical applications. Materials Today. 2015;18:447-458.

11. Zuo P, Lu X, Sun Z, Guo Y, He H. A review on syntheses, properties, characterization and bioanalytical applications of fluorescent carbon dots. Microchim Acta. 2016;183:519-542.

12. Wang YF, Hu A. Carbon Quantum Dots: synthesis, properties and applications. J Mater Chem C. 2014;2:6921-6939.

13. Wang L, Bi Y, Hou, J, Li H, Xu Y, Wang B, Ding H, Ding L. Facile, green and clean one-step synthesis of carbon dots from wool: Application as a sensor for glyphosate detection based on the inner filter effect. Talanta. 2016;160:268-275.

14. Sun YP, Zhou B, Lin $Y$, Wang W, Fernando KA, Pathak $P$, Meziani MJ, Harruff BA, Wang X, Wang H, Luo PG, Yang H, Kose ME, Chen B, Veca LM, Xie SY. Quantum-Sized Carbon Dots for Bright and Colorful Photoluminescence. J Am Chem Soc. 2006;128:7756-7757.

15. Thongpool V, Asanithi P, Limsuwan P. Synthesis of Carbon Particles using Laser Ablation in Ethanol. Procedia Engg. 2012;32:1054-1060.

16. Lu J, Yang J, Wang J, Lim A, Wang S, Loh KP. One-pot synthesis of fluorescent carbon nanoribbons, nanoparticles, and graphene by the exfoliation of graphite in ionic liquids. ACS Nano. 2009;3:2367-2375.

17. Yao S, Hu Y, Li G. A one-step sonoelectrochemical preparation method of pure blue fluorescent carbon nanoparticles under a high intensity electric field. Carbon. 2014;66:77-83.

18. Zhang Z, Duan Y, Yu Y, Yan Z, Chen J. Carbon Quantum Dots: synthesis, characterization, and assessment of cytocompatibility. J Mater Sci Mater Med. 2015;26:213.

19. Zhang X, He X, Li Y, Zhang Z, Ma Y, Li F, Liu J. A cytotoxicity study of fluorescent carbon nanodots using human bronchial epithelial cells. $J$ Nanosci Nanotechnol. 2013;13:5254-5259.

20. Guan W, Gu W, Ye L, Guo C, Su S, Xu P, Xue M. Microwave-assisted polyol synthesis of carbon nitride dots from folic acid for cell imaging. Int $J$ Nanomedicine. 2014;9:5071-5078.

21. Wang W, Li Y, Cheng L, Cao Z, Liu W. Water-soluble and phosphoruscontaining carbon dots with strong green fluorescence for cell labeling. J Mater Chem B. 2014;2:46-48.

22. Kang YF, Li YH, Fang YW, Xu Y, Wei XM, Yin XB. Carbon Quantum Dots for zebrafish fluorescence imaging. Sci Rep. 2015;5:11835.

23. Zong J, Zhu Y, Yang X, Shen J, Li C. Synthesis of photoluminescent carbogenic dots using mesoporous silica spheres as nanoreactors. Chem Comm (Camb). 2011;47:764-766.

24. Yang Y, Wu D, Han S, Hu P, Liu R. Bottom-up fabrication of photoluminescent carbon dots with uniform morphology via a soft-hard template approach. Chem Comm (Camb). 2013;49:4920-4922.

25. Lai CW, Hsiao YH, Peng YK, Chou PT. Facile synthesis of highly emissive carbon dots from pyrolysis of glycerol; gram scale production of carbon dots/mSiO2for cell imaging and drug release. J Mater Chem. 2012;22:14403-14409.

26. Zhang M, Bai L, Shang W, Xie W, Ma H, Fu Y, Fang D, Sun H, Fan L, Han M, Liu C, Yang S. Facile synthesis of water-soluble, highly fluorescent graphene Quantum Dots as a robust biological label for stem cells. J Mater Chem. 2012;22:7461-7467.

27. Shinde DB, Pillai VK. Electrochemical preparation of luminescent graphene Quantum Dots from multiwalled carbon nanotubes. Chemistry. 2012;18:12522-12528.

28. Thambiraj S, Shankaran DR. Green synthesis of highly fluorescent Carbon Quantum Dots from sugarcane bagasse pulp. Applied Surface Sci. 2016;30:435-443.

29. Zhao C, Li W, Liang Y, Tian Y, Zhang Q. Synthesis of BiOBr/Carbon quantum microspheres with enhanced photoactivity and photostability under visible light irradiation. Applied Catalysis A General. 2016;527:127136.

30. Liu R, Wu D, Feng X, Müllen K. Bottom-up fabrication of photoluminescent graphene Quantum Dots with uniform morphology. J Am Chem Soc. 2011;133:15221-15223.

31. Mao LH, Tang WQ, Deng ZY, Liu SS, Wang CF, Chen S. Facile access to white fluorescent carbon dots toward light-emitting devices. Ind Eng Chem Res. 2014;53:6417-6425.

32. Peng J, Gao W, Gupta BK, Liu Z, Romero-Aburto R, Ge L, Song L, Alemany LB, Zhan X, Gao G, Vithayathil SA, Kaipparettu BA, Marti AA, Hayashi T, Zhu JJ, Ajayan PM. Graphene Quantum Dots derived from carbon fibers. Nano Lett. 2012;12:844-849.

33. Tian L, Ghosh D, Chen W, Pradhan S, Chang X, Chen S. Nanosized carbon particles from natural gas soot. Chem Mater. 2009;21:2803-2809. 
34. Li H, He X, Liu Y, Yu H, Kang Z, Lee ST. Synthesis of fluorescent carbon nanoparticles directly from active carbon via a one- step ultrasonic treatment. Mater Res Bull. 2011;4:147-151.

35. Wang F, Xie Z, Zhang H, Liu CY, Zhang YG. Highly luminescent organosilane-functionalized carbon dots. Adv Funct Mater. 2011;21:10271031.

36. Dong Y, Shao JW, Chen C, Li H, Wang R, Chi Y, Lin X, Chen G. Blue luminescent graphene $\mathrm{QD}$ and graphene oxide prepared by tuning the carbonization degree of citric acid. Carbon. 2012;50:4738-4743.

37. Tang L, Ji R, Cao X, Lin J, Jiang H, Li X, Teng KS, Luk CM, Zeng S, Hao J, Lau SP. Deep ultraviolet photoluminescence of water-soluble selfpassivated graphene Quantum Dots. ACS Nano. 2012;6:5102-5110.

38. Yang ST, Wang X, Wang H, Lu F, Luo PG, Cao L, Meziani MJ, Liu JH, Liu Y, Chen M, Huang Y, Sun YP. Carbon dots as nontoxic and high performance fluorescence imaging agents. J Phys Chem C Nanomater Interfaces. 2009;113:18110-18114.

39. Tao H, Yang K, Ma Z, Wan J, Zhang Y, Kang Z, Liu Z. In vivo NIR fluorescence imaging, biodistribution, and toxicology of photoluminescent carbon dots produced from carbon nanotubes and graphite. Small. 2012;8:281-290.

40. Li N, Liang X, Wang L, Li Z, Li P, Zhu Y, Song J. Biodistribution study of carbogenic dots in cells and in vivo for optical imaging. J Nanopart Res. 2012;14:1177.

41. Xu Y, Jia XH, Yin XB, He XW, Zhang YK. Carbon quantum dot stabilized gadolinium nanoprobe prepared via a one-pot hydrothermal approach for magnetic resonance and fluorescence dual modality bioimaging. Anal Chem. 2014;86:12122-12129.

42. Chen C, Wang H. Biomedical Applications and Toxicology of Carbon Nanomaterials. Wiley; 2016:60-62.

43. Shen LM, Liu J. New Development in Carbon Quantum Dots technical applications. Talanta. 2016;157:245-256.
44. Lim SY, Shen W, Gao Z. Carbon Quantum Dots and their applications. Chem Soc Rev. 2015;44:362-381.

45. Liu Z, Chen X, Zhang X, Gooding JJ, Zhou Y. Carbon-Quantum-Dots loaded mesoporous silica nanocarriers with $\mathrm{pH}$-switchable zwitterionic surface and enzyme responsive pore-cap for targeted imaging and drug delivery to tumor. Adv Healthc Mater. 2016;5:1401-1407.

46. Campos BB, Caceres RC, Bandosz TJ, Jimenez JJ, Castellon ER, Esteves da Silva JCG, Algarra M. Carbon dots coated with vitamin B12 as selective ratiometric nanosensor for phenolic carbofuran. Sensors Actuators B Chem. 2017;239:553-561.

47. Loo AH, Sofer Z, Bousa D, Ulbrich P, Bonanni A, Pumera M. Carboxylic C Quantum Dost as a Fluorescent Sensing Platform for DNA Detection. ACS Appl Mater Interfaces. 2016;8:1951-1957.

48. Zhu S, Meng Q, Wang L, Zhang J, Song Y, Jin H, Zhang K, Sun H, Wang $H$, Yang B. Highly photoluminescent carbon dots for multicolor patterning, sensors, and bioimaging. Angewandte Chem Int Ed Engl. 2013;52:3953-3957.

49. Cao L, Wang X, Meziani MJ, Lu F, Wang H, Luo PG, Lin Y, Harruff BA, Veca LM, Murray D, Xie SY, Sun YP. Carbon dots for multiphoton bioimaging. J Am Chem Soc. 2007;129:11318-11319.

50. Luo PG, Sahu S, Yang ST, Sonkar SK, Wang J, Wang H, LeCroy GE, Cao L, Sun YP. Carbon "quantum" dots for optical bioimaging. J Mater Chem B. 2013;1:2116-2127.

51. Fernando KA, Sahu S, Liu Y, Lewis WK, Guliants EA, Jafariyan A, Wang $P$, Bunker CE, Sun YP. Carbon quantum dost and applications in photocatalytic energy conversion. ACS Appl Mater Interfaces. 2015;7:8363-8376.

52. Elhissi AM, Ahmed W, Hassan IU, Dhanak VR, D'Emanuele A. Carbon nanotubes in cancer therapy and drug delivery. J Drug Del. 2012;2012:837327. 